\title{
Reação de Híbridos de Milho à Podridão Branca da Espiga
}

\author{
Justino L. Mario ${ }^{1}$, Erlei M. Reis ${ }^{1} \&$ Emídio R. Bonato ${ }^{2}$ \\ ${ }^{1}$ Faculdade de Agronomia e Medicina Veterinária, Universidade de Passo Fundo, Cx. Postal 611, Passo Fundo, RS, \\ CEP 99001-970, e-mail:erleireis@uol.com.br; ${ }^{2}$ Embrapa Trigo, Passo Fundo, RS
}

(Aceito para publicação em 16/10/2002)

Autor para correspondência: Erlei Melo Reis

MARIO, J.L., REIS, E.M. \& BONATO, E.R. Reação de híbridos de milho inoculados, em espigas, com Diplodia maydis. Fitopatologia Brasileira 28:155-158. 2003.

\section{RESUMO}

Neste trabalho, avaliou-se a reação de seis híbridos de milho (Zea mays) (AG 9012, C 808, P 3041, C 901, XL 212 e X 9403) de germoplasmas diferentes, a Diplodia maydis inoculados artificalmente nas espigas e à infecção natural de D. maydis $e$ de $D$. macrospora. O híbrido X 9403 apresentou a menor incidência de grãos infetados e o rendimento de grãos superior dos demais híbridos; o híbrido XL 212 apresentou incidência e rendimento de grãos intermediários. Esses dois híbridos possuem textura de grãos dentados. Os híbridos P 3041, AG 9012 e C 808, com textura de

grãos duro, apresentaram rendimentos inferiores e reações variáveis a $D$. maydis e a $D$. macrospora. Esses resultados mostraram que existe variabilidade entre híbridos quanto à reação à podridão da espiga causada por D. maydis e a D. macrospora. Na identificação de materiais resistentes, se sugere utilizar métodos artificiais de inoculação, visando aumentar a pressão de seleção e confiabilidade nos resultados. resistência.

Palavras-chave adicionais: Zea mays, Diplodia maydis,

\section{ABSTRACT}

\section{Reaction of corn hybrids to white ear rot}

This research assessed the reaction of six corn (Zea mays) hybrids (AG 9012, C 808, P 3041, C 901, XL 212 and X 9403), from different germplasms, to inoculation of Diplodia maydis. The hybrid X 9403 had the lowest incidence of infected grains and the highest kernel yield. The hybrid XL 212 showed intermediate incidence and yield. These two materials have dent grain texture.
The hybrids P 3041, AG 9012, and C 808, which have flint grain texture, showed variable reaction to $D$. maydis and $D$. macrospora in grains and had lower kernel yields than the dent grain materials. Results from this research show differences among corn hybrids regarding their reactions to $D$. maydis. This suggests the utilization of artificial inoculation to increase disease pressure through artificial inoculation.

\section{INTRODUÇÃO}

O milho (Zea mays L.) é cultivado praticamente em todos os estados brasileiros. Na região Sul, é a segunda cultura em importância econômica e em área cultivada.

As doenças do milho ocorrem praticamente em todos os locais onde o cereal é cultivado (Shurtleff, 1992). Os fungos Diplodia maydis (Berk.) Sacc., D. macrospora Earle e Fusarium moniliforme Sheld e F. graminearum (Schw) são os principais agentes causadores de podridões do colmo e da espiga, originando os chamados "grãos ardidos", que reduzem o rendimento e depreciam a qualidade do produto (Eddins, 1930; Koehler \& Boewe, 1957; Pereira \& Pereira, 1976; Klapproth \& Hawk, 1991; Dorrance et al., 1998).

As condições climáticas da região Sul, períodos com dias quentes, temperaturas diurnas entre 25 a $27^{\circ} \mathrm{C}$ e noturnas entre 12 a $15^{\circ} \mathrm{C}$, são favoráveis ao desenvolvimento de doenças incitadas por Diplodia spp. (Pereira, 1995). Segundo esse autor, existem diferenças de comportamento entre

\footnotetext{
*Parte da dissertação de mestrado do primeiro autor. Universidade de Passo Fundo (2000).
}

híbridos quanto a resistência à podridão da espiga causada por D. maydis. Nos últimos anos, as doenças de espiga estão preocupando os produtores, pela exigência das indústrias em adquirir matéria-prima de melhor qualidade. Este trabalho teve por objetivo avaliar a reação de alguns híbridos de milho quando inoculados com $D$. maydi e a infecção natural de $D$. maydis e de D. macrospora, no campo.

\section{MATERIAL E MÉTODOS}

\section{Delineamento experimental}

O delineamento experimental foi o de blocos ao acaso, com parcelas subdivididas e quatro repetições. Os germoplasmas (seis híbridos) constituíram as parcelas principais, e os métodos de inoculação (natural, aspersão e deposição), as subparcelas. As unidades experimentais constaram de duas linhas de $5 \mathrm{~m}$, com 25 plantas cada e espaçamento de $0,8 \mathrm{~m}$ entre linhas. $\mathrm{O}$ experimento foi conduzido nas safras 1995/96 e 1996/97.

\section{Implantação do experimento}

$\mathrm{O}$ experimento foi implantado em latossolo vermelho 


\section{J.L. Mario et al.}

escuro, sob o sistema de plantio direto. A semeadura foi realizada com semeadora de parcela, distribuindo-se as sementes a uma profundidade média de $6 \mathrm{~cm}$. Vinte e dois dias após a semeadura, realizou-se um desbaste, de tal forma que as plantas remanescentes ficaram espaçadas entre si de $20 \mathrm{~cm}$. A adubação de base, a nitrogenada em cobertura e os tratos culturais foram feitos de acordo com as recomendações técnicas para a cultura do milho no Rio Grande do Sul (Recomendações, 1996).

\section{Culivares}

Foram testados seis híbridos de milho, sendo três com grãos de textura dura (AG 9012, C 808 e P 3041) e três de textura mole (C 901, XL 212 e X 9403). A escolha dos híbridos baseou-se nas características descritas por Klapproth \& Hawk (1991), e em observações no campo quanto ao comportamento de híbridos de milho frente às podridões da espiga sob condições de infecção natural. Os híbridos com grãos de textura dura apresentaram as seguintes características agronômicas: espigas bem empalhadas e baixa incidência de fungos em seus grãos (P 3041); espigas com empalhamento médio, porém com intensidade moderada da podridão branca da espiga (AG 9012); mau empalhamento e intensidade elevada da doença (C 808). Os híbridos de grãos dentados foram escolhidos com base nas mesmas características agronômicas preestabelecidas, ou seja, com espigas bem empalhadas e baixa incidência de podridão de espiga (XL 212); espigas com empalhamento médio, porém com intensidade moderada da doença (X 9403), e espigas mal empalhadas e intensidade elevada da podridão da espiga $(\mathrm{C}$ 901).

\section{Metodologia de inoculação}

Utilizou-se no presente trabalho uma mistura de isolados de D. maydis, cujo inóculo foi aumentado em grãos de sorgo [Sorghum bicolor (L.) Moench], em frascos Erlenmeyers de $500 \mathrm{ml}$ de volume. Em ambos os métodos de inoculação artificial, utilizaram-se $5 \mathrm{ml}$ de uma suspensão de 40.000 conídios $\mathrm{ml}^{-1}$ de $D$. maydis por espiga, dez dias após $100 \%$ da floração feminina ter sido observada. Na inoculação por deposição, a suspensão de esporos foi colocada no interior da bainha foliar, atrás da espiga e acima do pedúnculo. No caso da inoculação por aspersão, a suspensão foi aspergida sobre os estigmas das espigas (Klapproth \& Hawk, 1991; Bensch et al., 1992).

\section{Colheita}

A colheita das espigas de cada cultivar foi realizada quando os grãos atingiram um teor de umidade de 18-24\% (Recomendações, 1996). Próximo da maturação, amostras prévias foram utilizadas para determinação da umidade, selecionando-se três plantas ao acaso/cultivar/repetição das linhas da bordadura. A principal característica agronômica considerada para essa seleção foi quando as espigas, por observação visual, apresentavam as brácteas secas. A partir desse momento, procedeu-se à colheita para as amostragens de grãos. Cada amostra originou-se de três espigas que foram debulhadas manualmente e cujos grãos foram misturados para a determinação do teor de umidade que foi quantificada com um aparelho marca Dole, modelo 400. Quando o teor de umidade da espiga atingiu o teor de umidade estabelecido, todas as espigas da primeira linha de cada parcela foram colhidas manualmente.

\section{Patologia em grãos}

Primeiramente, 200 grãos/tratamento, acondicionados em um saquinho de filó, foram lavados em água corrente de torneira por $30 \mathrm{~s}$. Logo após, imergiram-se os grãos em uma solução de etanol a 95\% e, em seguida, imersos em uma solução de hipoclorito de sódio a 2,0\% e agitados em um agitador magnético durante $3 \mathrm{~min}$. Em câmara de fluxo laminar, os grãos foram enxaguados em $500 \mathrm{ml}$ de água destilada esterilizada (ADE) e colocados a secar sobre papelfiltro esterilizado. A seguir, dez grãos foram eqüidistantemente dispostos em caixas de gerbox (unidade experimental) com três folhas de papel-filtro umedecidas com ADE. Foram incubados 200 grãos/tratamento na proporção de 50 grãos/ gerbox. A incubação ocorreu em câmara de crescimento a uma temperatura de $25 \pm 2{ }^{\circ} \mathrm{C}$ e fotoperíodo de $12 \mathrm{~h}$, até a diferenciação das colônias de D. maydis e posterior formação de picnídios sobre os grãos, conforme método descrito por Mario \& Reis (2001).

\section{Análise estatística}

Os resultados de incidência dos fungos em semente e de rendimento de grãos foram submetidos à análise de variância. $\mathrm{O}$ dados dos fungos foram transformados em Arco Seno $(\sqrt{ }(\mathrm{x} / \mathrm{k})]$, segundo Alves et al. (1993), por não apresentarem distribuição normal através do teste de Lilliefors. Para as médias do rendimento de grãos, não houve transformação por apresentarem distribuição normal. Os resultados das médias foram comparados pelo teste Tukey a 5\% de probabilidade utilizando-se o programa computacional Sannest, versão 7.0.

\section{RESULTADOS E DISCUSSÃO}

\section{Comparação de métodos de inoculação sobre o rendimento de grãos}

No experimento de 1995/96, o rendimento médio de grãos dos seis híbridos inoculados foi estatisticamente reduzido apenas pelo método de inoculação por aspersão, embora não tenha diferido do método de deposição. No entanto, os rendimentos foram semelhantes entre o método de deposição e o de infecção natural. No experimento conduzido em 1996/97, não houve efeito significativo dos métodos de inoculação sobre o rendimento de grãos. O mesmo fato ocorreu para a média geral de rendimento de grãos nos dois anos em que o experimento foi conduzido (Tabela 1).

Os dados obtidos são semelhantes aos relatados por Thompson et al. (1971), que apontam a podridão de espiga como um fator redutor mais de qualidade e não tanto de 
TABELA 1 - Comparação de métodos de inoculação de Diplodia maydis, em espigas de milho (Zea mays), no rendimento de grãos, nas safras 1995/96 e 1996/97, em Coxilha, RS

\begin{tabular}{lccc}
\hline \hline \multirow{2}{*}{ Método } & \multicolumn{3}{c}{ Rendimento de grãos $\left(\mathbf{k g ~ h a ̈} \mathbf{a}^{\mathbf{1}}\right)$} \\
\cline { 2 - 4 } & $\mathbf{1 9 9 5 / 9 6}$ & $\mathbf{1 9 9 6 / 9 7}$ & Média \\
\hline Infecção Natural & $9.202 \mathrm{a}$ & $9.323 \mathrm{a}$ & $9.262 \mathrm{a}$ \\
Aspersão & $8.862 \mathrm{~b}$ & $9.463 \mathrm{a}$ & $9.162 \mathrm{a}$ \\
Deposição & $9.008 \mathrm{a} \mathrm{b}$ & $9.231 \mathrm{a}$ & $9.119 \mathrm{a}$
\end{tabular}

Médias seguidas de letras distintas na colunas diferem entre si pelo teste Tukey a $5 \%$.

C.V. $=6,7 \%$; D.M.S. $5 \%=300,1$.

quantidade. Afirmam, ainda, os autores que a podridão de espigas não está relacionada com a podridão do colmo, a qual, sim, causa reduções no rendimento.

Incidência natural de $D$. macrospora e $D$. maydis em grãos Embora tenha sido inoculado apenas D. maydis, quando se procedeu à avaliação da incidência em grãos, constatou-se com frequiência, a presença de D. macrospora, não inoculado. No experimento conduzido em 1995/96, a incidência média de $D$. maydis em grãos foi de $3,25 \%$ e a de D. macrospora, de $12,32 \%$ (Tabela 2). É provável que em trabalhos semelhantes conduzidos no campo, ainda que seja inoculada apenas uma espécie de Diplodia, pode haver a ocorrência de outra e em maior incidência. Este trabalho mostra a importância de quantificar-se em laboratório a incidência do patógeno alvo do estudo. Apesar da inoculação, a incidência de $D$. maydis foi quatro vezes inferior à de $D$. macrospora. Esses valores podem ser considerados insuficientes para permitir diferenciar níveis de resistência (Tabela 2). Segundo Flett \& McLaren (1994), para que sejam detectadas diferenças quanto à reação de híbridos, é necessária uma incidência mínima de espigas infetadas de 17\%. No experimento conduzido em 1996/97, a incidência de $D$. maydis foi de $12,36 \%$ e a de D. macrospora, de $23,15 \%$ (Tabela 2). Esse aumento da incidência em grãos pode ser atribuído à maior disponibilidade de inóculo nos restos culturais, de onde os esporos podem ter sido liberados e transportados pelo vento até os sítios de infecção, conforme quantificado e discutido por Mario \& Reis (2003). Segundo Del Rio (1990), Flett \& McLaren (1994) e Reis \& Casa (1996), o aumento de intensidade das podridões de espiga e do colmo está relacionado com a densidade de inóculo na fonte. No trabalho de Mário \& Reis (2003), observou-se uma maior densidade de conídios nos restos culturais e no ar em 1996/ 97 em relação a 1995/96, concordando com a afirmação dos autores citados. Não se encontrou na literatura consultada uma justificativa para a maior incidência de D. macrospora em grãos de milho em relação a $D$. maydis. Provavelmente, D. macrospora seja um competidor mais eficiente pelos sítios de infecção do milho que $D$. maydis como abordado por Del Rio (1990).Os híbridos testados apresentaram diferentes incidências de ambas as espécies de Diplodia nos grãos avaliados (Tabela 2). O híbrido X 9403 apresentou, na média, a menor incidência de $D$. maydis $(2,86 \%)$ e $D$. macrospora $(12,38 \%)$ em grãos. Embora, para D. macrospora, esse híbrido não tenha diferido do AG 9012, C 901, e XL 212. O híbrido $\mathrm{X} 9403$ possui grãos do tipo dentado e por isso essa característica pode explicar a sua reação. A reação desse híbrido, por outro lado, contraria as observações feitas por Sutton \& Waterston (1966), os quais relatam que materiais de grãos do tipo duro são mais resistentes à infecção de $D$. maydis. Os demais híbridos apresentaram interação híbrido e patógeno, alternando a incidência de grãos naturalmente infetados e a freqüência de cada espécie de Diplodia. Esses resultados mostram que existe variabilidade genética a reação de $D$. maydis e de D. macrospora, sendo possível a seleção de genótipos resistentes às duas espécies.

\section{Rendimento de grãos dos híbridos}

Na média dos experimentos, o híbrido X 9403 apresentou um rendimento de grãos significativamente superior aos demais (Tabela 3 ) e também a menor incidência de Diplodia spp. em grãos (Tabela 2). Os híbridos XL 212 e C 901 apresentaram um rendimento intermediário, enquanto

TABELA 2 - Incidência (\%) de Diplodia maydis e D. macrospora em grãos, em diferentes híbridos de milho (Zea mays) sob infecção natural, nas safras 1995/96 e 1996/97, em Coxilha, RS

\begin{tabular}{|c|c|c|c|c|c|c|}
\hline \multirow{2}{*}{ Híbrido } & \multicolumn{2}{|c|}{ 1995/1996 } & \multicolumn{2}{|c|}{ 1996/1997 } & \multicolumn{2}{|c|}{ Média } \\
\hline & D. maydis & D. macrospora & D. maydis & D. macrospora & D. maydis & D. macrospora \\
\hline P 3041 & $2,00^{\mathrm{y}}$ & 16,44 & 12,53 & 33,74 & $7,26 \mathrm{ab}^{\mathrm{z}}$ & $25,09 \mathrm{a}$ \\
\hline C 808 & 4,00 & 10,94 & 12,27 & 31,78 & $8,13 \mathrm{ab}$ & $21,36 \mathrm{ab}$ \\
\hline XL 212 & 3,00 & 16,90 & 10,75 & 18,15 & $6,86 \mathrm{ab}$ & 17,52 bc \\
\hline C 901 & 5,00 & 11,13 & 18,40 & 20,36 & $11,70 \mathrm{a}$ & 15,74 bc \\
\hline AG 9012 & 5,00 & 9,84 & 15,00 & 18,85 & $10,00 \mathrm{ab}$ & 14,19 \\
\hline X 9403 & 0,50 & 8,72 & 5,23 & 16,04 & $2,86 \mathrm{c}$ & 12,38 \\
\hline Média & $3,25 b^{x}$ & $12,32 \mathrm{a}$ & $12,36 \mathrm{~b}$ & $23,15 \mathrm{a}$ & & \\
\hline
\end{tabular}

'Médias seguidas de letras distintas na coluna diferem entre si pelo teste Tukey a $5 \%$.

'Médias seguidas de letras distintas na linha diferem entre si pelo teste Tukey a $5 \%$.

${ }^{z}$ Média de 200 grãos em cada ano.

C.V. $=21,83 \%$; D.M.S. $5 \%=6,32$. 


\section{J.L. Mario et al.}

TABELA 3 - Rendimento de grãos de híbridos de milho (Zea mays) inoculados com Diplodia maydis, nas safras 1995/96 e 1996/97, em Coxilha, RS

\begin{tabular}{|c|c|c|c|c|}
\hline \multirow{2}{*}{ Híbrido } & \multicolumn{4}{|c|}{ "Rendimento de grãos $\left(\mathrm{kg} \text { hă }^{-1}\right)^{\mathrm{Z}}$} \\
\hline & $1995 / 96$ & $1996 / 97$ & Média & \\
\hline X 9403 & $10,129 \mathrm{a}$ & $10,641 \mathrm{a}$ & $10,385 \mathrm{a}$ & \\
\hline XL 212 & $9,815 \mathrm{a}$ & $9,228 \quad b$ & 9,521 & $\mathrm{~b}$ \\
\hline C 901 & $9,425 \mathrm{ab}$ & $9,585 \mathrm{~b}$ & 9,507 & $\mathrm{~b}$ \\
\hline P 3041 & $8,131 \quad \mathrm{~cd}$ & $9,058 \quad \mathrm{bc}$ & 8,594 & $\mathrm{c}$ \\
\hline AG 9012 & 8,874 bc & 8,264 & 8,569 & $\mathrm{c}$ \\
\hline C 808 & 7,769 & $9,258 \quad b$ & 8,513 & $\mathrm{c}$ \\
\hline
\end{tabular}

${ }^{2}$ Médias seguidas de letras distintas na coluna diferem entre si pelo teste Tukey a $5 \%$.

C.V. $=4,7 \%$; D.M.S. $5 \%=817,1$.

P 3041, AG 9012 e C 808 foram inferiores. Os híbridos XL 212 e C 901, que apresentaram uma posição intermediária no rendimento, tiveram reações diferentes à infecção natural dos grãos. Por outro lado, o XL 212 apresentou uma reação intermediária às duas espécies, enquanto o $\mathrm{C} 901$ teve reação intermediária para $D$. macrospora e alta incidência de $D$. maydis nos grãos. Os híbridos X 9403, XL 212 e C 901, que apresentaram rendimento de grãos de médio a superior, possuem grãos do tipo dentado (mole). Entretanto, os híbridos P 3041, AG 9012 e C 808, do tipo duro, tiveram rendimento médio inferior e apresentaram alternância quanto à reação de infecção natural em grãos para as espécies de Diplodia. Esses resultados confirmam o relato feito por Wiser et al. (1960), de que não existe germoplasma com resistência completa a $D$. maydis. Mostrou-se, assim, que existe variabilidade genética para os dois patógenos e que, através de um programa de melhoramento direcionado para esse fim, pode-se conseguir híbridos resistentes à podridão da espiga.

\section{REFERÊNCIAS BIBLIOGRÁFICAS}

ALVES, M.I.F., MACHADO, A.M. \& ZONTA, E.P. Tópicos especiais de estatística experimental utilizando o SANEST (Sistema de Análise Estatística para Microcomputadores). In: Simpósio de Estatística Aplicada à Experimentação Agronômica, 5. Reunião Anual da Sociedade Internacional de Biometria, 38, 1993.

BENSCH, M.J., VAN STADEN, J. \& RIJKENBERG, J.H.F. Time and site of inoculation of maize for optimum infection of ears by Stenocarpella maydis. Journal of Phytopathology 136:265-269. 1992. DEL RIO, L. Maiz muerto en Honduras provocado por el complejo
Diplodia y Fusarium. Manejo Integrado de Plagas 18:42-53. 1990. DORRANCE, A.E., HINKELMAN, K.H. \& WARREN, H.L. Diallel analysis of Diploida ear rot resistance in maize. Plant Disease 82:699703. 1998.

EDDINS, A.H. Dry rot of corn caused by Diplodia macrospora Earle. Phytopathology 20:439-448. 1930.

FLETT, B.C. \& McLAREN, N.W. Optimum disease potential for evaluating resistance to Stenocarpella maydis ear rot corn hybrids. Plant Disease 78:587-589. 1994.

KLAPPROTH, C.J. \& HAWK, A.J. Evaluation of four inoculation techniques for infecting corn ears with Stenocarpella maydis. Plant Disease 75:1057-1060. 1991.

KOEHLER, B. \& BOEWE, G.H. Causes of corn stalk rot in Illinois. Plant Disease Reporter 41:501-504. 1957

MARIO, J.L. \& REIS, E.M. Método simples para diferenciar Diplodia macrospora de D. maydis em testes de patologia de sementes de milho. Fitopatologia Brasileira 26:670-672. 2001.

MARIO, J.L. \& REIS, E.M. Quantificação do inóculo de Diplodia macrospora e de D. maydis em restos culturais, no ar e sua relação com a infecção em grãos de milho. Fitopatologia Brasileira 28:143147. 2003.

PEREIRA, O.A.P. Situação atual de doenças da cultura do milho no Brasil e estratégias de controle. In: Resistência Genética de Plantas a Doenças. Piracicaba. Departamento de Genética, Escola Superior de Agricultura Luis de Queiroz, Universidade de São Paulo. 1995. pp.25-30.

PEREIRA, O.A.P. \& PEREIRA, W.S.P. Estudo de Diplodia zeae (Shw.) Lev. e Fusarium moniliforme (Sheldon) em colmos de milho. Summa Phytopathologica 2:157-165. 1976.

RECOMENDAÇÕES técnicas para a cultura do milho no estado do Rio Grande do Sul. Fundação Estadual de Pesquisa Agropecuária; Associação de Empreendimentos de Assistência Técnica e Extensão Rural; Federação das Cooperativas de Trigo e Soja do RS Ltda. Porto Alegre. FEPAGRO. Boletim Técnico, 3. 1996.

REIS, E.M. \& CASA, R.T. Manual de identificação e controle de doenças de milho. Passo Fundo. Aldeia Norte Editora. 1996.

SHURTLEFF, M.C. A compendium of corn diseases. St. Paul, Minnesota. American Phytopathological Society. 1992.

SUTTON, B.C. \& WATERSTON, J.M. Diplodia maydis. London. Comonwealth Mycological Institute. C.M.I. Descriptions of pathogenic fungi and bacteria, $\mathrm{N}^{\circ}$ 84. 1966.

THOMPSON, D.L., VILLENA, W.L. \& MAXWELL, J.D. Correlation between Diplodia stalk and ear rot of corn. Plant Disease Reporter 55:158-162. 1971.

WISER, W.J., KRAMER, H.H. \& ULLSTRUP, A.J. Evaluating inbred lines of corn for resistance to Diplodia ear rot. Agronomy Journal 52:624-26. 1960. 